\title{
Sugammadex-induced atropine-resistant bradycardia: clinical, pathophysiologic, and electrocardiographic considerations
}

\author{
Nicholas G. Kounis ${ }^{1 *}\left(\mathbb{D}\right.$, loanna Koniari ${ }^{2}$, George D. Soufras ${ }^{3}$, Grigorios Tsigkas ${ }^{1}$, Panagiotis Plotas', \\ Periklis Davlouros ${ }^{1}$ and George Hahalis ${ }^{1}$
}

Keywords: Anaphylaxis, Anesthesia, Kounis syndrome, Sugammadex

To the Editor:

In the very interesting report published in JA Clinical Reports [1], a 50-year-old woman without previous comorbidities, developed bradycardia and hypotension following intravenous sugammadex administration during anesthesia for transabdominal hysterectomy and right salpingo-oophorectomy. Propofol, fentanyl, remifentanyl, rocuronium, and levobupivacaine had been given preoperatively. Atropine was not effective but adrenaline recovered blood pressure and heart rate. Allergic skin signs were absent and tryptase and histamine were not measured. Electrocardiographic ST elevation in lead aVR and widespread ST depression were present. This report raises the following important issues:

\section{Perioperative medications}

All above medications including sugammadex have been incriminated to induce anaphylaxis and Kounis syndrome [2-5]. Drugs can act as antigens inducing immunoglobin E (IgE) antibodies that are attached to the mast cell surface. Anaphylaxis ensues when antigens are bridged with their corresponding IgE antibodies and making at least 1000 bridges. IgE antibodies with different specificities can have additive effects and small, even sub-threshold numbers can join forces and trigger the cells to release their mediators $[6,7]$.

\footnotetext{
*Correspondence: ngkounis@otenet.gr

'Department of Cardiology, University of Patras Medical School, Queen Olgas Square, 7 Aratou Street, 26221 Patras, Greece

Full list of author information is available at the end of the article
}

\begin{abstract}
Absence of skin manifestations in anaphylaxis
Tryptase or histamine was not measured due to absence of rash or itching. This had rendered the diagnosis of anaphylaxis difficult. Severe anaphylaxis and Kounis syndrome without skin involvement have been already reported $[8,9]$. The bradycardia and hypotension following sugammadex could have been attributed to reduced cardiac output from leakage of plasma and volume loss. Volume loss reduces venous return and hampers or delays the release of mediators for reaching the skin areas and thus none applying their action [10].
\end{abstract}

\section{The "neglected aVR" lead}

The patient's electrocardiogram showed a unique sign of ST elevation in lead aVR, with reciprocal ST depression in the majority of other leads. These findings constitute new electrocardiographic manifestations of Kounis syndrome. The lead aVR, until recent years, was regarded as the "neglected lead" [11]. However, reports have shown that ST-segment elevation of more than $1.0 \mathrm{~mm}$ in lead aVR associated with widespread ST-segment depression in inferolateral leads, as in the described patient, best identifies severe left main or 3-vessel disease with $80 \%$ sensitivity and $93 \%$ specificity [12]. Urgent coronary angiography is necessary to confirm this and the diagnosis is high-risk non-ST segment elevation acute coronary syndrome that requires urgent revascularization and medical treatment that includes anti-platelets, aspirin, and heparin [13]. However, the same electrocardiographic findings can be present in type A dissecting aneurysm affecting the ascending aorta that expands and 
presses the left main artery and the coronary ostia. Whereas clinical picture is of acute myocardial infarction, the treatment is completely different and includes emergency surgery and avoidance of anti-platelets, aspirin, and heparin [14]. Such dilemma is easily solved by trans-thoracic echocardiography. The described patient was obese but had normal preoperative 12-lead electrocardiogram and past history free of comorbidities. In view of her perioperative electrocardiographic changes and the suspicion of type I Kounis syndrome angiographic evaluation postoperatively would have been helpful.

All above show that Kounis syndrome is a condition with variety of etiology, clinical, and electrocardiographic manifestations. During their everyday practice, anesthetists and surgeons should be always brought it in mind.

\section{Acknowledgements}

None

\section{Authors'contributions}

NGK and GDS wrote the initial draft of the manuscript. IK, PD, and GH revised the manuscript for intellectual content. PP contributed to the acquisition and collected the literature. All authors approved the final version of the manuscript and agree to be accountable for all aspects of the work in ensuring that questions related to the accuracy or integrity of any part of the work are appropriately investigated and resolved. All authors read and approved the final manuscript.

\section{Funding}

The authors declare that they received no funding for this work

\section{Availability of data and materials}

Not applicable

Ethics approval and consent to participate

Not applicable

\section{Consent for publication}

Not applicable

\section{Competing interests}

The authors declare that they have no competing interests.

\section{Author details}

'Department of Cardiology, University of Patras Medical School, Queen Olgas Square, 7 Aratou Street, 26221 Patras, Greece. ${ }^{2}$ Electrophysiology and Device Department, University Hospital of South Manchester NHS Foundation Trust, Manchester, UK. ㄹ. Department of Cardiology, "Saint Andrews" State General Hospital, Patras, Greece.

Received: 30 March 2020 Accepted: 22 April 2020

Published online: 07 May 2020

\section{References}

1. Yoshida T, Sumi C, Uba T, Miyata H, Umegaki T, Kamibayashi T. A rare case of atropine-resistant bradycardia following sugammadex administration. JA Clin Rep. 2020;6:18.

2. Yanai M, Ariyoshi K. Two cardiac arrests that occurred after the administration of sugammadex: a case of Kounis syndrome. Case Rep Emerg Med. 2020;2020:6590101.

3. Fagley RE, Woodbury A, Visuara A, Wall M. Rocuronium-induced coronary vasospasm--"Kounis syndrome". Int J Cardiol. 2009;137:e29-32.

4. Kounis N, Kounis G. Anaphylactic cardiovascular collapse during anesthesia: the Kounis acute hypersensitivity syndrome seems to be the most likely cause. J Korean Med Sci. 2013;28:638-9.
5. Kounis NG, Kounis GN, Soufras GD. Amikacin, bupivacaine, fentanyl and Kounis syndrome. J Pharmacol Pharmacother. 2014:5:169-71.

6. Nopp A, Johansson SG, Lundberg M, Oman H. Simultaneous exposure of several allergens has an additive effect on multisensitized basophils. Allergy. 2006:61:1366-8.

7. Kounis NG, Koniari I, Plotas P, Hahalis G. Not many is the good, but in the good, the many. Menos es más. Rev Esp Anestesiol Reanim. 2019;66:351-2.

8. Andrews ID, Scheinman P. Systemic hypersensitivity reaction (without cutaneous manifestations) to an implantable cardioverter-defibrillator. Dermatitis. 2011;22:161-4.

9. Adachi $H$, Ihara M, Nojima Y, Kurimoto T, Nanto S. Kounis syndrome caused by anaphylaxis without skin manifestations after cefazolin administration. J Allergy Clin Immunol Pract. 2019;7:317-9.

10. Kounis NG, Cervellin G, Koniari I, Bonfanti L, Dousdampanis P, Charokopos $\mathrm{N}$, et al. Anaphylactic cardiovascular collapse and Kounis syndrome: systemic vasodilation or coronary vasoconstriction? Ann Transl Med. 2018;6: 332.

11. Kosuge M, Ebina T, Hibi K, Morita S, Endo M, Maejima N, et al. An early and simple predictor of severe left main and/or three-vessel disease in patients with non-ST segment elevation acute coronary syndrome. Am J Cardiol. 2011;107:495-500

12. Ching S, Ting SM. The forgotten lead: aVR in left main disease. Am J Med. 2015;128:e11-3.

13. Cayla G, Silvain J, Collet JP, Montalescot G. Updates and current recommendations for the management of patients with non-ST-elevation acute coronary syndromes: what it means for clinical practice. Am J Cardiol. 2015;115(5 suppl):10A-22A.

14. Kosuge M, Uchida K, Imoto K, Isoda S, Karube N, Ebina T, et al. Prognostic value of ST-segment elevation in lead aVR in patients with type A acute aortic dissection. J Am Coll Cardiol. 2015;65:2570-1.

\section{Publisher's Note}

Springer Nature remains neutral with regard to jurisdictional claims in published maps and institutional affiliations.

\section{Submit your manuscript to a SpringerOpen ${ }^{\circ}$ journal and benefit from:}

- Convenient online submission

- Rigorous peer review

- Open access: articles freely available online

- High visibility within the field

- Retaining the copyright to your article

Submit your next manuscript at $>$ springeropen.com 